Article

\title{
Strain-Compensated InGaAsP Superlattices for Defect Reduction of InP Grown on Exact-Oriented (001) Patterned Si Substrates by Metal Organic Chemical Vapor Deposition
}

\author{
Ludovico Megalini ${ }^{1, *}$, Simone Tommaso Šuran Brunelli ${ }^{1}$, William O. Charles ${ }^{2}$, Aidan Taylor ${ }^{3}$, \\ Brandon Isaac $^{3}$, John E. Bowers ${ }^{1,3}$ (i) and Jonathan Klamkin ${ }^{1}$ \\ 1 Department of Electrical and Computer Engineering, University of California Santa Barbara, \\ Santa Barbara, CA 93106, USA; ssuranbrunelli@umail.ucsb.edu (S.T.Š.B.); bowers@ece.ucsb.edu (J.E.B.); \\ klamkin@ece.ucsb.edu (J.K.) \\ 2 SUNY Polytechnic Institute, Albany, NY 12222, USA; wcharles@sunypoly.edu \\ 3 Materials Department, University of California Santa Barbara, Santa Barbara, CA 93106, USA; \\ aidantaylor@ucsb.edu (A.T.); brandonjisaac@ucsb.edu (B.I.) \\ * Correspondence: megalini@ucsb.edu; Tel.: +1-805-689-0211
}

Received: 28 January 2018; Accepted: 20 February 2018; Published: 26 February 2018

\begin{abstract}
We report on the use of InGaAsP strain-compensated superlattices (SC-SLs) as a technique to reduce the defect density of Indium Phosphide (InP) grown on silicon (InP-on-Si) by Metal Organic Chemical Vapor Deposition (MOCVD). Initially, a $2 \mu \mathrm{m}$ thick gallium arsenide (GaAs) layer was grown with very high uniformity on exact oriented (001) $300 \mathrm{~mm} \mathrm{Si}$ wafers; which had been patterned in $90 \mathrm{~nm} \mathrm{~V}$-grooved trenches separated by silicon dioxide $\left(\mathrm{SiO}_{2}\right)$ stripes and oriented along the [110] direction. Undercut at the $\mathrm{Si} / \mathrm{SiO}_{2}$ interface was used to reduce the propagation of defects into the III-V layers. Following wafer dicing; $2.6 \mu \mathrm{m}$ of indium phosphide (InP) was grown on such GaAs-on-Si templates. InGaAsP SC-SLs and thermal annealing were used to achieve a high-quality and smooth InP pseudo-substrate with a reduced defect density. Both the GaAs-on-Si and the subsequently grown InP layers were characterized using a variety of techniques including $X$-ray diffraction (XRD); atomic force microscopy (AFM); transmission electron microscopy (TEM); and electron channeling contrast imaging (ECCI); which indicate high-quality of the epitaxial films. The threading dislocation density and RMS surface roughness of the final InP layer were $5 \times 10^{8} / \mathrm{cm}^{2}$ and $1.2 \mathrm{~nm}$; respectively and $7.8 \times 10^{7} / \mathrm{cm}^{2}$ and $10.8 \mathrm{~nm}$ for the GaAs-on-Si layer.
\end{abstract}

Keywords: InGaAsP strain compensated superlattices; MOCVD; hetero-epitaxy on $\mathrm{Si}$; InP on $\mathrm{Si}$; GaAs on Si

\section{Introduction}

The direct growth of $\mathrm{InP}$ and $\mathrm{GaAs}$ on Silicon (Si) is of strong interest for the fabrication of monolithically integrated lasers in silicon photonics $(\mathrm{SiPh})$ and, more generally, to realize opto-electronic integrated circuits (OEICs). Large-scale manufacturing would prefer monolithic solutions to techniques like flip-chip and wafer bonding, although these are currently more mature [1,2]. In particular, hetero-epitaxy by MOCVD is attractive due to the ability of this technique to grow a broad range of compounds for photonics and electronics devices in large-scale and high-yield [3].

However, the direct heteroepitaxy of $\mathrm{InP} / \mathrm{GaAs}$ on $\mathrm{Si}$ is extremely challenging: the large lattice mismatches between InP, GaAs, and $\mathrm{Si}\left(\varepsilon_{I n P / S i} \approx 8 \%, \varepsilon_{G a A s / S i} \approx 4 \%\right)$, their different polarities and thermal expansion coefficient cause the formation in high density of defects, including anti-phase domains (APDs), stacking faults, twins, threading, and misfit dislocations, which typically exceed 
$1 \times 10^{9} / \mathrm{cm}^{2}$ [4] and as a consequence they reduce significantly the performance and reliability of the fabricated devices. Therefore defect engineering techniques have been used to improve the epitaxial film quality including growth of Ge [5], GaAs [6], or GaP [7] thin buffer layer either on exact oriented (001) or off-cut $\mathrm{Si}$ wafers [8], use of thermal cycling both during the different layers growth and at the end of the final epitaxial stack [9], selective area growth (SAG) [10] often combined with aspect ratio trapping (ART) [11-14], strain engineering by growth of graded buffer layers like InAlAs [15], and strained layer superlattices (SLSLs) [16], typically used as threading dislocation (TDs) filtering. Indeed, these last two techniques tend to favor TD movement and interaction [17], which can cause TD annihilation or movement toward the edge of the wafer, ultimately resulting in wide defect-free regions of the epitaxial structure. Strained layer superlattices have been extensively studied and successfully employed in GaAs-on-Si growth [18-22], GaN-on-sapphire [23,24], and GaN-on-Si [25,26], while their use in InP-on-Si has been rather limited [27].

In this work, we propose the use InGaAsP strain-compensated superlattices as an additional tool to reduce the defect density in InP-on-Si. To the best of our knowledge, this is the first report showing strain compensation using InGaAsP alloys for both the tensile and compressive layers. The use of quaternary compounds is particularly interesting because it allows us to independently control the strain and the composition of each strained layer. Moreover, the InGaAsP material system does not suffer of the typical growth issues of III-nitride compounds so that all the compressive and tensile layers can be grown at their optimum temperature without the need of long waiting time for temperature ramp up and cool down, as is the case in the InGaN/AlGaN system [28].

\section{Materials Growth}

The epitaxial structure was grown entirely by MOCVD. Initially, a $2 \mu \mathrm{m}$ thick GaAs layer was grown on a $300 \mathrm{~mm}$ patterned Si wafer (Figure 1a). The pattern consisted of $90 \mathrm{~nm}$ wide trenches separated by $65 \mathrm{~nm}$ wide $\mathrm{SiO}_{2}$ stripes. V-grooves were formed by etching the $\mathrm{Si}$ trenches with dilute potassium hydroxide $(\mathrm{KOH})$ at $70{ }^{\circ} \mathrm{C}$ such that the growth was initiated on $\{111\}$ Si surface to avoid anti-phase domains formation (APDs) [29]. Additionally, a small undercut was formed at the $\mathrm{Si} / \mathrm{SiO}_{2}$ interface to exploit the defect necking mechanism and reduce most of the stacking fault propagation from the Si device layer into the III-V layer (Figure 1b) [30,31].
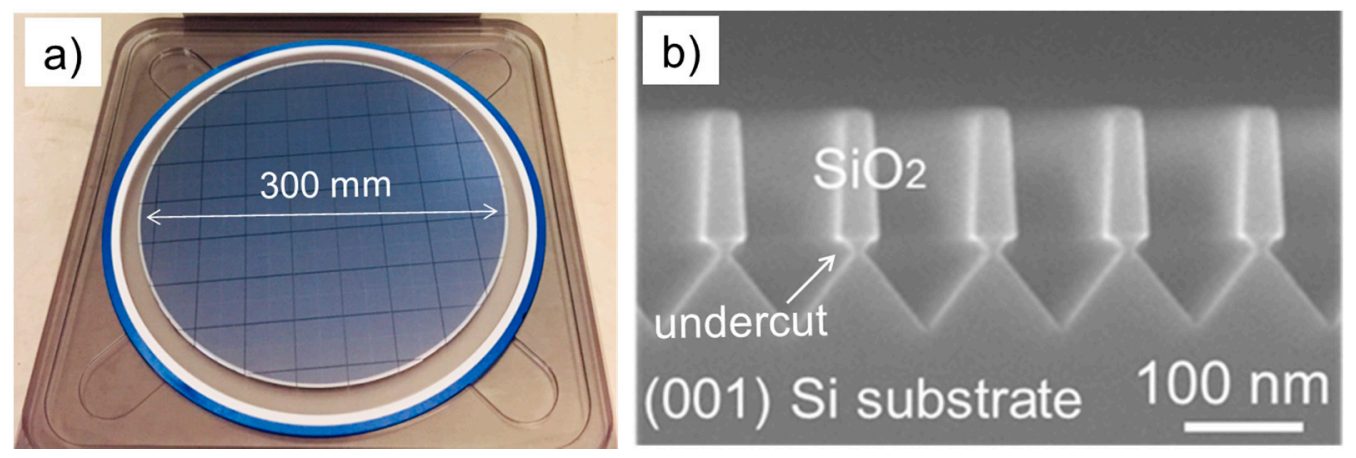

Figure 1. (a) Photo illustrating the $300 \mathrm{~mm}$ exact (001) Si wafer used a substrate for the III-V growth; (b) cross-section SEM image of the Si wafer patterning.

\subsection{GaAs on $\mathrm{Si}$}

A GaAs buffer layer was initially grown on $\mathrm{Si}$ (GaAs-on-Si) and used as a platform for the subsequent InP-based structure. A patterned Si wafer was loaded into an Aixtron Crius-R reactor that can accommodate one $300 \mathrm{~mm}$ silicon wafer and it was exposed to vaporized hydrofluoric acid (HF) in a pre-clean reactor chamber to remove the oxide between the trenches. Then the wafer was transferred to the reactor growth chamber where it was heated to $900{ }^{\circ} \mathrm{C}$ for $10 \mathrm{~min}$ in a high pressure $\mathrm{H}_{2}$ to remove the native oxide and to further clean the wafer surface. After exposing the wafer surface to 
tertiarybutylarsine (TBAs), a thin $(\sim 7 \mathrm{~nm})$ nucleation layer was grown at a temperature of $400{ }^{\circ} \mathrm{C}$ using trimethylgallium (TMGa) and tertiarybutylarsine (TBAs). The TBAs flash and the low temperature layer help to accommodate the lattice mismatch between the III-V and the Si substrate and the III-V layers [32]. Then a high quality GaAs layer was grown in a temperature range of $600{ }^{\circ} \mathrm{C}$ to $650{ }^{\circ} \mathrm{C}$ using TMGa and arsine $\left(\mathrm{AsH}_{3}\right)$ with a $\mathrm{V} / \mathrm{III}$ ratio of 100 . The wafer was annealed in a temperature range of $6500^{\circ} \mathrm{C}$ to $750{ }^{\circ} \mathrm{C}$ in an arsenic rich ambient for $20 \mathrm{~min}$.

\subsection{InP and Strain Compensated InGaAsP Superlattice on $\mathrm{Si}$}

The $300 \mathrm{~mm}$ GaAs-on-Si wafer was diced in $2 \times 2 \mathrm{~cm}^{2}$ pieces to allow loading into a different Aixtron MOCVD reactor. Following an oxide desorption step at $550{ }^{\circ} \mathrm{C}$ under TBAs flow, the temperature was decreased to $430{ }^{\circ} \mathrm{C}$ to deposit a thin $(\sim 20 \mathrm{~nm})$ low-temperature InP nucleation layer to accommodate the lattice mismatch between $\mathrm{InP}$ and GaAs $\left(\varepsilon_{I n P / G a A s} \approx 4 \%\right)$. The V/III ratio was 628. Next, the temperature was increased to $610^{\circ} \mathrm{C}$ and the InP growth rate was progressively increased until a growth of $3.7 \AA / \mathrm{s}$ was reached [33]. Trimethylindium (TMIn) and tertiarybutyl phosphine (TBP) were used as group III and V precursors, respectively. After $600 \mathrm{~nm}$ thick InP was grown, four $I n_{x_{1}} G a_{1-x_{1}} A s_{y_{1}} P_{1-y_{1}} / I n_{x_{2}} G a_{1-x_{2}} A s_{y_{2}} P_{1-y_{2}}$ strain compensated superlattices were inserted. The superlattices were separated by a $300 \mathrm{~nm}$ thick $\mathrm{InP}$ spacer. Each layer of the first two superlattices had a strain of $|0.5| \%$, while the third and fourth superlattices were made of layers having each a strain of $|1| \%$ and $|1.5| \%$, respectively. The epitaxial stack ended with a $600 \mathrm{~nm} \mathrm{InP}$ cap layer. Finally, an annealing under TBP flow at $610{ }^{\circ} \mathrm{C}$ for $10 \mathrm{~min}$ was carried out to favor the InP surface smoothing [34]. The reactor pressure was maintained at 350 Torr during the all growth. The final epitaxial structure is shown in Figure 2.

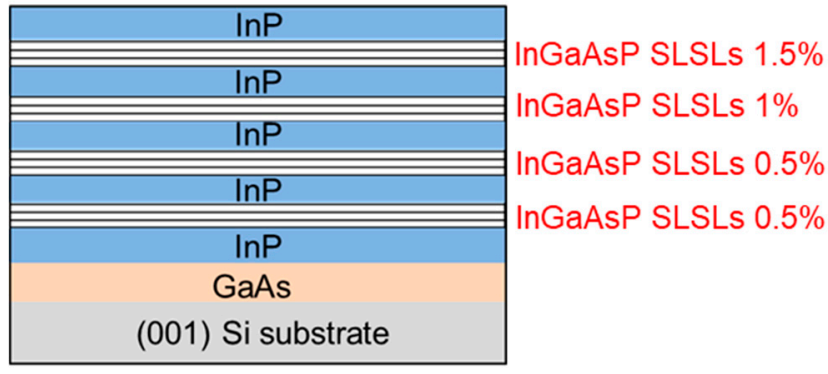

Figure 2. Schematic of the epitaxial stack.

\section{Materials Characterization}

The epitaxial layers were characterized by a variety of techniques. First of all, we verified the uniformity of the GaAs layer grown on the $300 \mathrm{~mm}$ patterned Si wafer, being the growth of high quality materials with high uniformity while maintaining a high throughput one of the III-V on Si monolithic integration key requirement. All these features are typical of the MOCVD growth technique. Later, we characterized the InP-on-GaAs-on-Si epitaxial quality, in particular, we studied the design and the impact of the InGaAsP superlattice on reducing the defect density.

\subsection{GaAs on $\mathrm{Si}$}

The uniformity and the quality of the GaAs layer were analyzed by X-ray diffraction using a PANalytical MRD PRO high resolution X-ray diffractometer (XR-XRD, PANalytical solutions, Almelo, Netherland) with a Cu k $\alpha 1$ (1.5405 $\AA$ ) source operated at $40 \mathrm{kV}$ voltage and $45 \mathrm{~mA}$ current. The (004) $\omega / 2 \theta$ s triple axis scan clearly shows both the GaAs and the Si peak at $32.95^{\circ}$ and $34.67^{\circ}$, respectively (Figure 2a) while a double axis configuration was used for on axis (004) $\omega$-rocking curves. The Full width half maximum (FWHM) was $167 \mathrm{arcsec}$, with a standard deviation of $\sim 7 \%$ across the $300 \mathrm{~mm}$ Si wafers. 
The small difference in FWHM of the scan perpendicular vs. parallel to the trench orientation suggests a slight difference in the defect distribution. This has been attributed to the aspect ratio trapping technique [35]. The threading dislocation density was estimated to be $8.5 \times 10^{7} / \mathrm{cm}^{2} \mathrm{by}$ electron contrast channeling imaging (ECCI) and the RMS roughness was $10.0 \mathrm{~nm}$ as measured by atomic force microscopy (AFM, Bruker Nano, Billerica, MA, USA) as shown in Figure 3c,d, respectively. The relatively high roughness is mainly attributed to the desorption of arsenic during the high temperature anneal step.
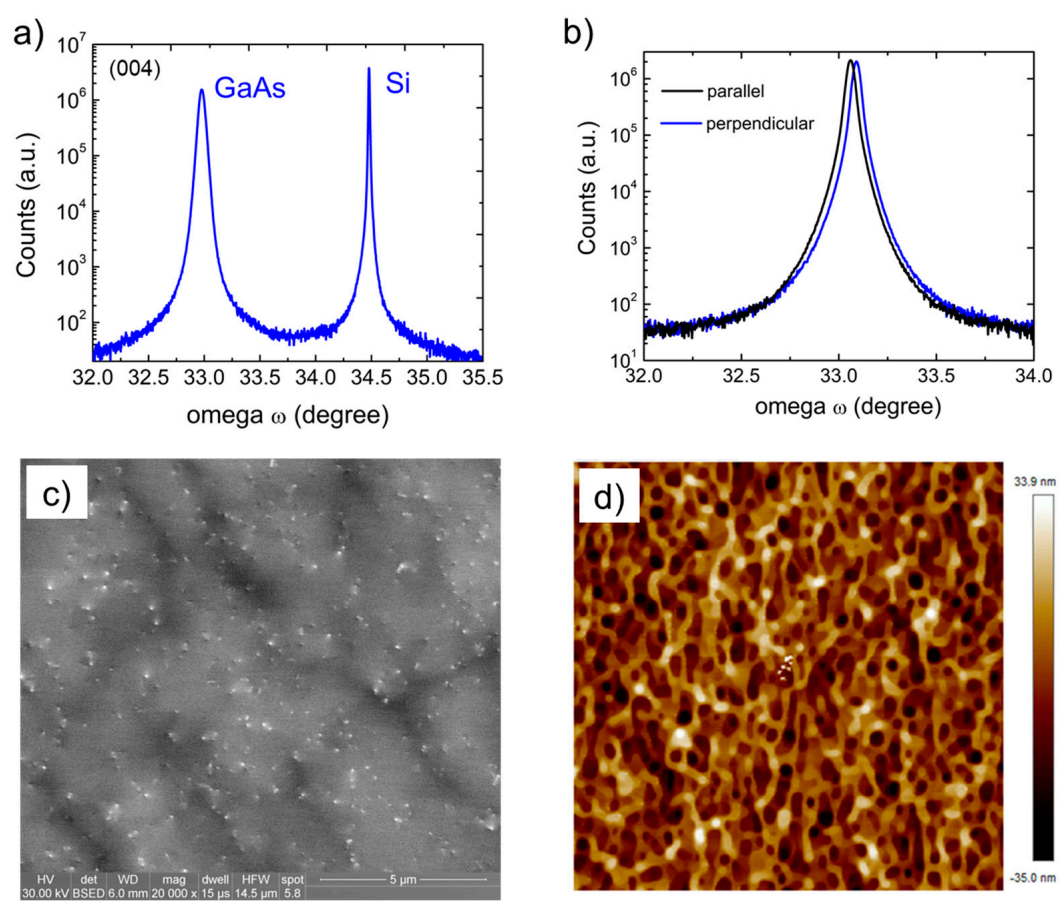

Figure 3. (a) $\omega-2 \theta$ scan; (b) w rocking curve; (c) ECCI; and (d) AFM scan of GaAs on Si epitaxial structure. AFM scan is over an area $5 \times 5 \mu \mathrm{m}^{2}$.

\subsection{InP-on-GaAs-on-Si}

The InP and the $I n_{x} G a_{1-x} A s_{y} P_{1-y}$ strain compensated superlattices grown on the GaAs-on-Si were preliminarily characterized by X-ray diffraction. Figure $4 a$ show the (004) $\omega / 2 \theta$ s triple axis configuration of the final epitaxial structure. The $I n_{x} G a_{1-x} A s_{y} P_{1-y}$ superlattices appear as two shoulders symmetric to the InP peak. The RMS roughness of the final structure is $1.2 \mathrm{~nm}$, as shown in Figure $4 \mathrm{~b}$.
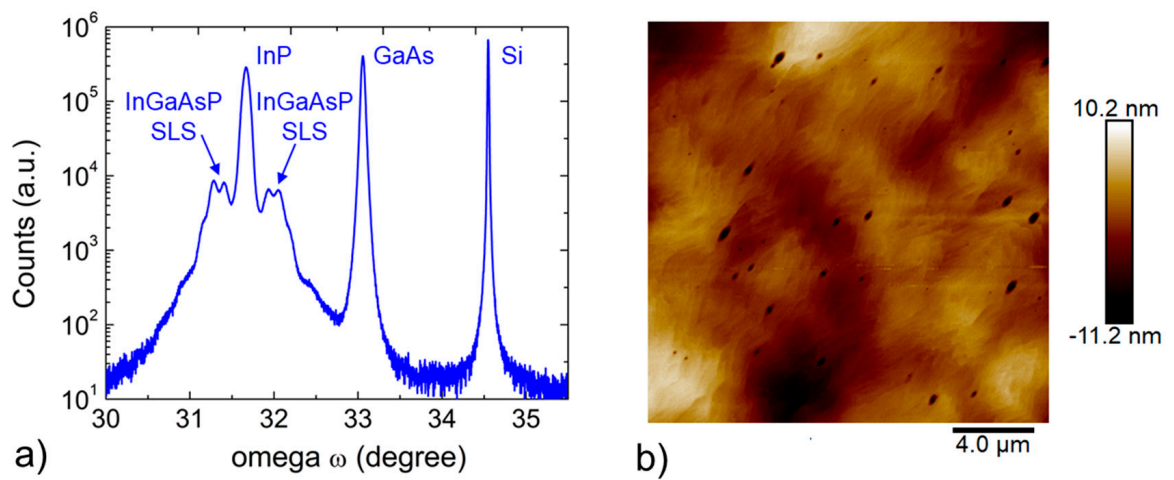

Figure 4. (a) $\omega-2 \theta$ scan and (b) AFM scan of the final epitaxial structure. 


\subsection{InGaAsP Strain Compensated Superlattice}

Four strain compensated superlattices (SC-SLs) were inserted in the InP layer. Each superlattice consisted of $4 \times$ (changed, pls confirm) pairs of $\operatorname{In}_{x_{1}} G a_{1-x_{1}} A s_{y_{1}} P_{1-y_{1}} / I n_{x_{2}} G a_{1-x_{2}} A s_{y_{2}} P_{1-y_{2}}$. The composition and thickness of each layer had been previously characterized on bulk InP substrate such that each compressive and tensile strained layer was grown coherently to InP. Figure 5a,b show the reciprocal space mapping (RSM) around (115) off-axis Bragg reflection of the 1\% compressive strained $I n_{x_{1}} G a_{1-x_{1}} A s_{y_{1}} P_{1-y_{1}}$ and $1 \%$ tensile $I n_{x_{2}} G a_{1-x_{2}} A s_{y_{2}} P_{1-y_{2}}$ layer.
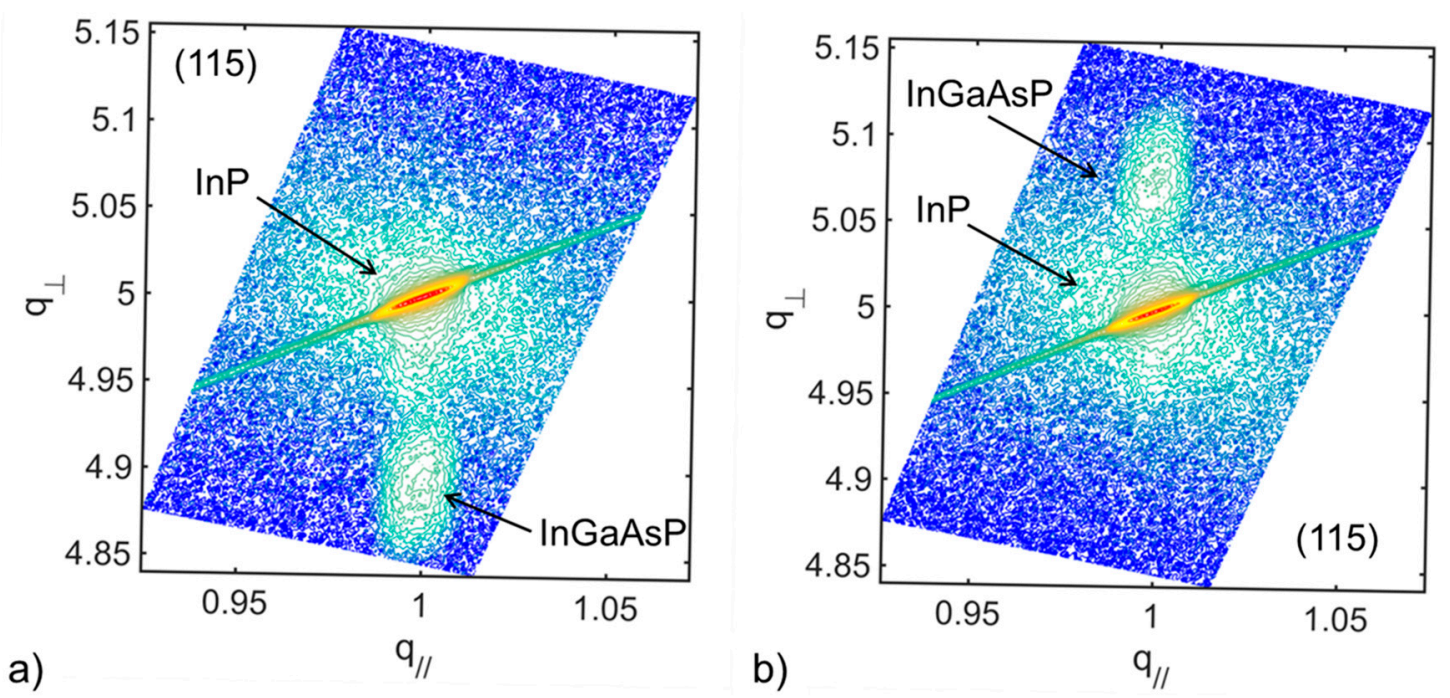

Figure 5. RSM map of (a) 1\% compressive and (b) 1\% tensile strained InGaAsP layer on bulk InP.

\section{Discussion}

Strain has been used as a powerful tool in the design of multi-quantum-well (MQW) active region of high-performance laser [36]. In particular, strain compensation has proven to be advantageous to devices reliability [37] by improving their thermal and structural stability [38]. Strain compensated structures emitting at $1550 \mathrm{~nm}$ have manifested stronger photoluminescence and narrower FHWM spectra [39] and $1.06 \mu \mathrm{m}$ optical modulators have shown improved performance [40].

Strain compensated superlattices are also beneficial to hetero-epitaxial growth because the driving force for the generation of misfit dislocation is reduced compared to the uncompensated structure [41,42].

In this work, the strain of each superlattice was obtained by alternating $\operatorname{In}_{x} G a_{1-x} A s_{y} P_{1-y}$ layers such that their strain was equal in magnitude and opposite in sign in order to obtain strain compensation. The layer thickness was kept $\sim 15 \%$ below the Matthew-Blakeslee critical thickness $h_{\mathrm{c}}$ for each specific strain in order to avoid the layer relaxation. The biaxial strain component $\varepsilon_{x y}$ of a strained InGaAsP layer grown on a relaxed InP layer perpendicular to the growth direction is defined as

$$
\varepsilon_{x y}=\frac{a_{I n P}-a_{I n_{x} G a_{1-x} A s_{y} P_{1-y}}}{a_{I n_{x} G a_{1-x} A s_{y} P_{1-y}}}
$$

and the average lattice constant $\left\langle a_{\text {pair }}\right\rangle$ of each strained layer pair is

$$
\left\langle a_{\text {pair }}\right\rangle=\frac{t_{\text {compressive }} \cdot a_{I n_{x_{1}} G a_{1-x_{1}} A s_{y_{1}} P_{1-y_{1}}+t_{\text {tensile }} \cdot a_{I n_{x_{2}} G a_{1-x_{2}} A s_{y_{2}} P_{1-y_{2}}}} t_{\text {compressive }}+t_{\text {tensile }}}{\text { com }}
$$

where $t_{\text {compressive }}\left(t_{\text {tensile }}\right)$ is the thickness of the compressive (tensile) layer of composition $a_{I n_{x_{1}} G a_{1-x_{1}} A s_{y_{1}} P_{1-y_{1}}}\left(a_{I n_{x_{2}} G a_{1-x_{2}} A s_{y_{2}} P_{1-y_{2}}}\right)$, respectively. 
Thus the average strain component of each superlattice is estimated as

$$
\varepsilon_{x y}=\frac{a_{\text {InP }}-\sum_{1}^{4}\left\langle a_{\text {pair }}\right\rangle}{\sum_{1}^{4}\left\langle a_{\text {pair }}\right\rangle}
$$

Table 1. Summary of the parameters of the superlattices used in this study.

\begin{tabular}{ccccc}
\hline Superlattice & Composition & Strain (\%) & PL (nm) & $\boldsymbol{h}_{\mathbf{c}}(\AA)$ \\
\hline 1st-c & $\mathrm{In}_{69.7} \mathrm{Ga}_{30.3} \mathrm{As}_{50} \mathrm{P}_{50}$ & +0.5 & 1164.3 & 244.6 \\
1 st-t & $\mathrm{In}_{69.7} \mathrm{Ga}_{30.3} \mathrm{As}_{80.9} \mathrm{P}_{19.1}$ & -0.5 & 1569.7 & 242.1 \\
2nd-c & $\mathrm{In}_{69.7} \mathrm{Ga}_{30.3} \mathrm{As}_{50} \mathrm{P}_{50}$ & +0.5 & 1164.3 & 244.6 \\
2nd-t & $\mathrm{In}_{69.7} \mathrm{Ga}_{30.3} \mathrm{As}_{80 .} \mathrm{P}_{19.1}$ & -0.5 & 1569.7 & 242.1 \\
3rd-c & $\mathrm{In}_{94.1} \mathrm{Ga}_{5.9} \mathrm{As}_{44.2} \mathrm{P}_{55.8}$ & +1.0 & 1302.8 & 86.2 \\
3rd-t & $\mathrm{In}_{63.2} \mathrm{Ga}_{36.8} \mathrm{As}_{49} \mathrm{P}_{51}$ & -1.0 & 1105.9 & 94.7 \\
4th-c & $\mathrm{In}_{52} \mathrm{Ga}_{48} \mathrm{As}_{58} \mathrm{P}_{42}$ & +1.5 & 1104.1 & 64.2 \\
4th-t & $\mathrm{In}_{90} \mathrm{Ga}_{10} \mathrm{As}_{68.7} \mathrm{P}_{31.3}$ & -1.5 & 1649.2 & 60.8 \\
\hline
\end{tabular}

Note: PL is the photoluminescence wavelength of the layer, $h_{\mathrm{c}}$ is the critical thickness and is estimated using [17].

The final structure presents a defect density of $\sim 5 \times 10^{8} / \mathrm{cm}^{2}$ as shown in Figure 6 a. The low RMS roughness value of $1.2 \mathrm{~nm}$ suggests that the strain compensated superlattices have also contributed to smoothing the relatively rough surface of the initial GaAs-on-Si epitaxial structure. Moreover, they have helped to filter most of the defects as illustrated in the TEM images of Figure 6b,c.

TEM images have also shown that the interfaces of the compensated strain superlattices are very sharp in the case of the first two superlattices (Figure 7a), differently from the third and fourth superlattices (Figure $7 \mathrm{~b}, \mathrm{c}$ ). This can be attributed to the extremely challenging task of growing a quaternary layer. Indeed, the flow of each metallorganic source needs to be monitored very carefully in order to control precisely both the layer thickness and composition. During the first two superlattices growth (absolute strain $=|0.5| \%$ ), only the TBAs flow was changed between the tensile and compressive layer and the others flows were maintained constant. On the other hand, in the case of the third and fourth superlattices, both the TBAs and the TMGa were changed in order to achieve a higher strain (absolute strain $=|1| \%$ and $|1.5| \%$, respectively). It is worth noting that the higher is the layer strain, the thinner is the grown layer. During all the superlattice growths, a $1.5 \mathrm{~s}$ pause was used between the compressive and tensile layer in order to evacuate the reactor chamber of residual gases.

Further improvement is expected by optimization of the strain of each layer of superlattices, in particular of the number of superlattice periods and their thickness, and of the growth conditions of the GaAs buffer layer.
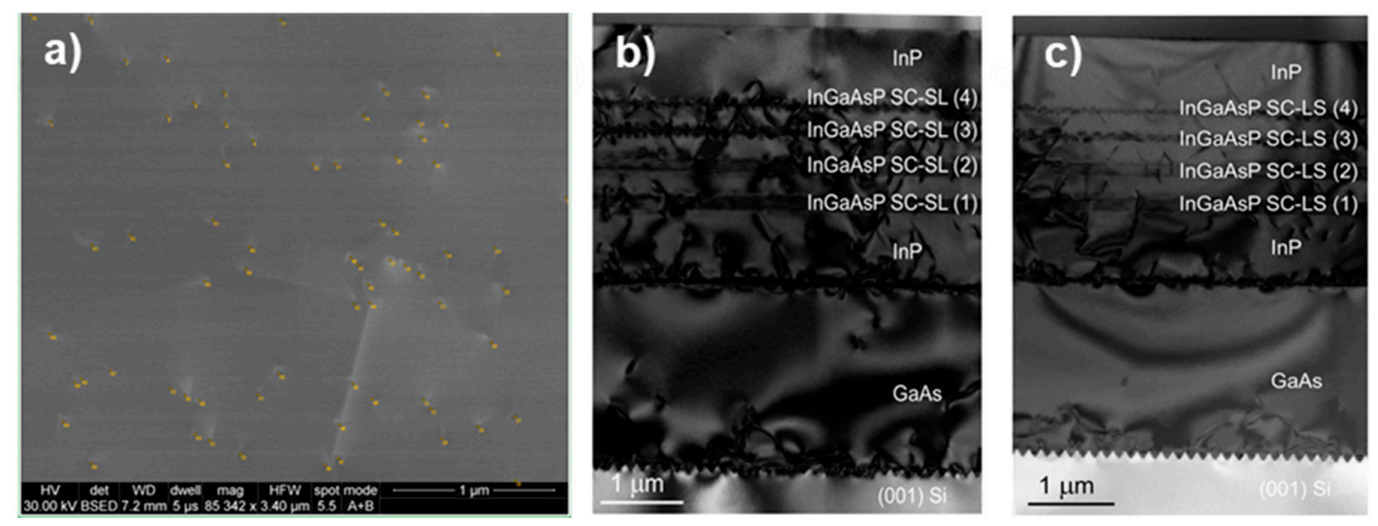

Figure 6. (a) Plain view ECCI image of the final epitaxial structure; (b,c) TEM cross-section TEM images showing the epitaxial stack. The SC-SLs are clearly visible and they are ordered 1-4 as listed in Table 1. 

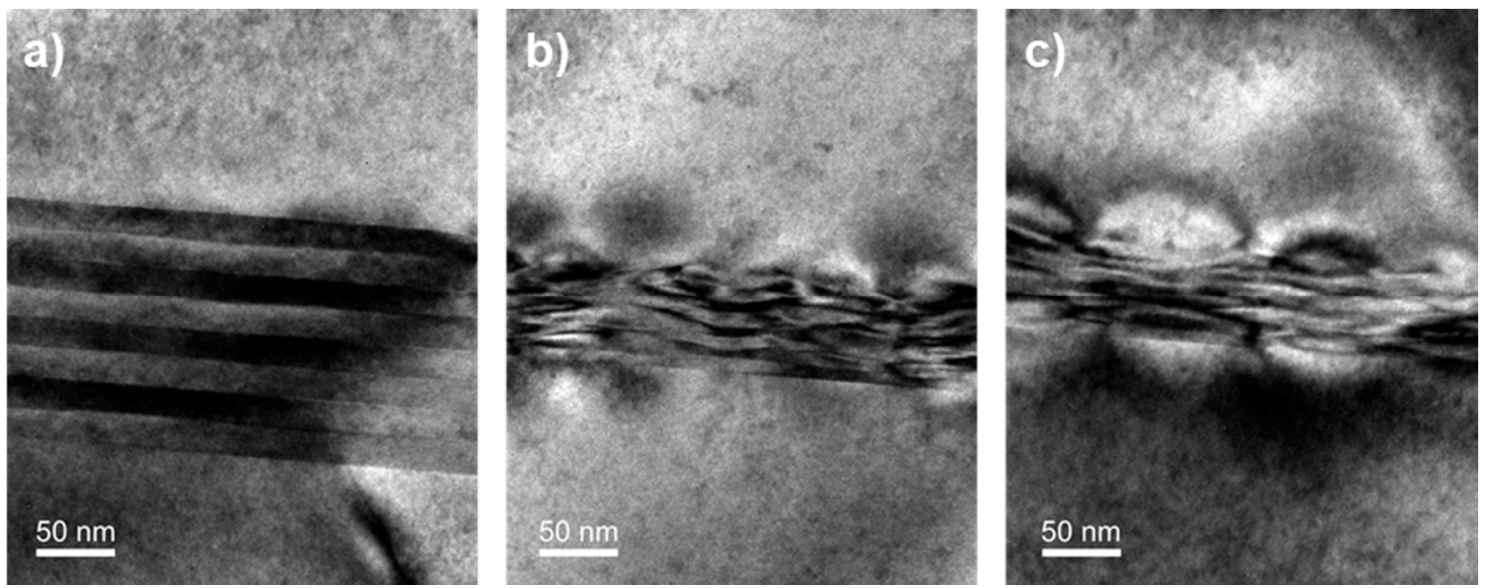

Figure 7. Dark field TEM images of the (a) $0.5 \%$; (b) $1 \%$; and (c) $1.5 \%$ strain compensated superlattices.

\section{Conclusions}

In this work, we have presented the growth by MOCVD of a smooth and high quality InP on exact (001) Si wafers using GaAs as buffer layer. Compensated strain InGaAsP superlattices were used as dislocation filters and they have shown to be helpful to reduce the propagation of threading dislocations from the substrate into the active region of the device. This approach is promising to grow InP virtual substrates directly on $300 \mathrm{~mm}$ exact (001) $\mathrm{Si}$ wafer grow by MOCVD which is necessary to monolithically integrate the next generation of photonic devices on $\mathrm{Si}$ with high-yield and high-throughput.

Acknowledgments: All of this research was supported by the American Institute for Manufacturing (AIM) Integrated Photonics. A portion of this work was done in the UCSB nanofabrication facility, part of the NSF NNIN network (ECS-0335765), as well as the UCSB CNSI and UCSB MRL, which are supported by the NSF MRSEC program (DMR1121053).

Author Contributions: Ludovico Megalini and Jonathan Klamkin conceived and designed the experiments; Ludovico Megalini., and William O. Charles grew the epitaxial materials; Aidan Taylor performed the TEM analysis; Ludovico Megalini, Simone Tommaso Šuran Brunelli, and Brandon Isaac performed the materials characterization and analyzed the data; all of the authors discussed the results; Ludovico Megalini. wrote the paper.

Conflicts of Interest: The authors declare no conflict of interest.

\section{References}

1. Song, B.; Megalini, L.; Dwivedi, S.; Ristic, S.; Klamkin, J. High-thermal-performance 3D hybrid silicon lasers. IEEE Photonics Technol. Lett. 2017, 29, 1143-1146. [CrossRef]

2. Liang, D.; Bowers, J.E. Recent progress in lasers on silicon. Nat. Photonics 2011, 4, 511-517. [CrossRef]

3. Stringfellow, G.B. Organometallic Vapor-Phase Epitaxy, Second Edition: Theory and Practice, 2nd ed.; Academic Press: Cambridge, MA, USA, 1998.

4. Kohen, D.; Sang, X.; Riko, N.; Made, I.; Heidelberger, C.; Hong Lee, K.; Eng, K.; Lee, K.; Fitzgerald, E.A. Preventing phase separation in MOCVD-grown InAlAs compositionally graded buffer on silicon substrate using InGaAs interlayers. J. Cryst. Growth 2017, 478, 64-70. [CrossRef]

5. Choi, D.; Harris, J.S.; Kim, E.; McIntyre, P.C.; Cagnon, J.; Stemmer, S. High-quality III-V semiconductor MBE growth on $\mathrm{Ge} / \mathrm{Si}$ virtual substrates for metal-oxide-semiconductor device fabrication. J. Cryst. Growth 2009, 311, 1962-1971. [CrossRef]

6. Sugo, M.; Yamaguchi, M. Buffer layer effects on residual stress in InP on Si substrates. Appl. Phys. Lett. 1989, 54, 1754. [CrossRef] 
7. Schulze, C.S.; Huang, X.; Prohl, C.; Füllert, V.; Rybank, S.; Maddox, S.J.; March, S.D.; Bank, S.R.; Lee, M.L.; Lenz, A. Atomic structure and stoichiometry of $\operatorname{In}(\mathrm{Ga}) \mathrm{As} / \mathrm{GaAs}$ quantum dots grown on an exact-oriented $\mathrm{GaP} / \mathrm{Si}(001)$ substrate. Appl. Phys. Lett. 2016, 108, 143101. [CrossRef]

8. Grundmann, M.; Krost, A.; Bimberg, D. Antiphase-domain-free InP on Si(001): Optimization of MOCVD process. J. Cryst. Growth 1991, 115, 150-153. [CrossRef]

9. Ababou, Y.; Desjardins, P.; Chennouf, A.; Leonelli, R.; Hetherington, D.; Yelon, A.; L'Esperance, G.; Masut, R.A. Structural and optical characterization of InP grown on Si(111) by metalorganic vapor phase epitaxy using thermal cycle growth. J. Appl. Phys. 1996, 80, 4997-5005. [CrossRef]

10. Fitzgerald, E.A.; Chand, N. Epitaxial necking in GaAs grown on pre-pattemed Si substrates. J. Electron. Mater. 1991, 20, 839-853. [CrossRef]

11. Guo, W.; Date, L.; Pena, V.; Bao, X.; Merckling, C.; Waldron, N.; Collaert, N.; Caymax, M.; Sanchez, E.; Vancoille, E.; et al. Anisotropic relaxation behavior of InGaAs/GaAs selectively grown in narrow trenches on (001) Si substrates. Appl. Phys. Lett. 2014, 105, 062101. [CrossRef]

12. Megalini, L.; Cabinian, B.C.; Zhao, H.; Oakley, D.C.; Bowers, J.E.; Klamkin, J. Large-area direct hetero-epitaxial growth of 1550-nm ingaasp multi-quantum-well structures on patterned exact-oriented (001) silicon substrates by metal organic chemical vapor deposition. J. Electron. Mater. 2017, 47, 982-987. [CrossRef]

13. Merckling, C.; Waldron, N.; Jiang, S.; Guo, W.; Richard, O.; Douhard, B.; Moussa, A.; Vanhaeren, D.; Bender, H.; Collaert, N.; et al. Heteroepitaxy of InP on Si (001) by selective-area metal organic vapor-phase epitaxy in sub-50 nm width trenches: The role of the nucleation layer and the recess engineering. J. Appl. Phys. 2013, 114, 033708. [CrossRef]

14. Li, J.Z.; Bai, J.; Park, J.S.; Adekore, B.; Fox, K.; Carroll, M.; Lochtefeld, A.; Shellenbarger, Z. Defect reduction of GaAs epitaxy on Si (001) using selective aspect ratio trapping. Appl. Phys. Lett. 2007, 91, 021114. [CrossRef]

15. Liu, W.K.; Lubyshev, D.; Fastenau, J.M.; Wu, Y.; Bulsara, T.; Fitzgerald, E.A.; Urteaga, M.; Ha, W.; Bergman, J.; Brar, B.; et al. Monolithic integration of InP-based transistors on Si substrates using MBE. J. Cryst. Growth 2009, 311, 1979-1983. [CrossRef]

16. Osbourn, G.C. Strained-layer superlattices: A brief review. IEEE J. Sel. Top. Quantum Electron. 1986, 22, 1677-1681. [CrossRef]

17. Matthews, J.W.; Blakeslee, A.E.; Mader, S. Use of misfit strain to remove dislocations from epitaxial thin films. Thin Solid Films 1976, 33, 253-266. [CrossRef]

18. Takano, Y.; Hisaka, M.; Fujii, N.; Suzuki, K.; Kuwahara, K.; Fuke, S. Reduction of threading dislocations by InGaAs interlayer in GaAs layers grown on Si substrates. Appl. Phys. Lett. 1998, 73, 2917-2919. [CrossRef]

19. MacPherson, G.; Goodhew, P.J. A refined scheme for the reduction of threading dislocation densities in $\mathrm{In}_{x} \mathrm{GaAs}_{1-x} \mathrm{As} / \mathrm{GaAs}$ epitaxial layers. J. Appl. Phys. 1996, 80, 6706-6710. [CrossRef]

20. Fritz, I.J.; Gourley, P.L.; Dawson, R.L.; Schirber, J.E. Electrical and optical studies of dislocation filtering in InGaAs/GaAs strained-layer superlattices. Appl. Phys. Lett. 1988, 53, 1098-1100. [CrossRef]

21. Tang, M.; Chen, S.; Wu, J.; Jiang, Q.; Kennedy, K.; Jurczak, P.; Liao, M.; Beanland, R.; Seeds, A.; Liu, H. Optimizations of defect filter layers for 1.3- $\mu \mathrm{m}$ InAs/GaAs quantum-dot lasers monolithically grown on $\mathrm{Si}$ substrates. IEEE J. Sel. Top. Quantum Electron. 2016, 22, 1900207. [CrossRef]

22. George, I.; Becagli, F.; Liu, H.Y.; Wu, J.; Tang, M.; Beanland, R. Dislocation filters in GaAs on Si. Semicond. Sci. Technol. 2015, 30, 114004. [CrossRef]

23. Nakamura, S.; Senoh, M.; Nagahama, S.; Iwasa, N.; Yamada, T.; Matsushita, T.; Kiyoku, H.; Sugimoto, Y.; Kozaki, T.; Umemoto, H.; et al. InGaN/GaN/AlGaN-based laser diodes with modulation-doped strained-layer superlattices grown on an epitaxially laterally overgrown GaN substrate. Appl. Phys. Lett. 1998, 72, 211-213. [CrossRef]

24. Kladko, V.; Kuchuk, A.; Lytvyn, P.; Yefanov, O.; Safriuk, N.; Belyaev, A.; Mazur, Y.I.; DeCuir, E.A.; Ware, M.E.; Salamo, G.J. Substrate effects on the strain relaxation in GaN/AlN short-period superlattices. Nanoscale Res. Lett. 2012, 7, 289. [CrossRef] [PubMed]

25. Ni, Y.; He, Z.; Yang, F.; Zhou, D.; Yao, Y.; Zhou, G.; Shen, Z.; Zhong, J.; Zhen, Y.; Wu, Z. Effect of AlN/GaN superlattice buffer on the strain state in GaN-on-Si(111) system. Jpn. J. Appl. Phys. 2014, 54, 015505. [CrossRef]

26. Lin, P.J.; Huang, S.Y.; Wang, W.K.; Chen, C.L.; Chung, B.C.; Wu, D.S. Controlling the stress of growing GaN on 150-mm Si (111) in an AlN/GaN strained layer superlattice. Appl. Surf. Sci. 2016, 362, 434-440. [CrossRef] 
27. Samonji, K.; Yonezu, H.; Takagi, Y.; Iwaki, K.; Ohshima, N.; Shin, J.K.; Pak, K. Reduction of threading dislocation density in InP-on-Si heteroepitaxy with strained short-period superlattices. Appl. Phys. Lett. 1996, 69, 100-102. [CrossRef]

28. Fireman, M.N.; Bonef, B.; Young, E.C.; Nookala, N.; Belkin, M.A.; Speck, J.S. Strain compensated superlattices on $m$-plane gallium nitride by ammonia molecular beam epitaxy. J. Appl. Phys. 2017, 122, 075105. [CrossRef]

29. Paladugu, M.; Merckling, C.; Loo, R.; Richard, O.; Bender, H.; Dekoster, J.; Vandervorst, W.; Caymax, M.; Heyns, M. Site Selective Integration of III-V materials on Si for nanoscale logic and photonic devices. Cryst. Growth Des. 2012, 12, 4696-4702. [CrossRef]

30. Megalini, L.; Bonef, B.; Cabinian, B.C.; Zhao, H.; Taylor, A.; Speck, J.S.; Bowers, J.E.; Klamkin, J. 1550-nm InGaAsP multi-quantum-well structures selectively grown on V-groove-patterned SOI substrates. Appl. Phys. Lett. 2017, 111, 032105. [CrossRef]

31. Li, Q.; Ng, K.W.; Lau, K.M. Growing antiphase-domain-free GaAs thin films out of highly ordered planar nanowire arrays on exact (001) silicon. Appl. Phys. Lett. 2015, 106, 072105. [CrossRef]

32. Orzali, T.; Vert, A.; O’Brien, B.; Herman, J.L.; Vivekanand, S.; Hill, R.J.W.; Karim, Z.; Papa Rao, S.S. GaAs on Si epitaxy by aspect ratio trapping: Analysis and reduction of defects propagating along the trench direction. J. Appl. Phys. 2015, 118, 105307. [CrossRef]

33. Megalini, L.; Cabinian, B.C.; Zhao, H.; Oakley, D.; Bowers, J.E.; Klamkin, J. Toward fully monolithic 1550-nm lasers on silicon by direct hetero-epitaxy growth on patterned substrates. In Proceedings of the CLEO: Applications and Technology, San Jose, CA, USA, 14-19 May 2017. [CrossRef]

34. Megalini, L.; Cabinian, B.C.; Bonef, B.; Zhao, H.; Mates, T.; Speck, J.S.; Bowers, J.E.; Klamkin, J. 1550-nm InGaAsP multi-quantum-well structures in InP nano-ridges by selective MOCVD growth on SOI substrates. In Proceedings of the Integrated Photonics Research, Silicon and Nanophotonics, New Orleans, LA, USA, 24-27 July 2017. [CrossRef]

35. Merckling, C.; Waldron, N.; Jiang, S.; Weiming, G.; Barla, K.; Heynsa, M.; Collaert, N.; Thean, A.; Vandervors, W. Selective-area metal organic Vapor-Phase Epitaxy of III-V on Si: What about defect density? ECS Trans. 2014, 64, 513-521. [CrossRef]

36. Coldren, L.A.; Corzine, S.W.; Mašanović, M. Gain and current relations. In Diode Lasers and Photonic Integrated Circuits, 2nd ed.; Chang, K., Ed.; Wiley: New York, NY, USA, 2012; pp. 157-246.

37. Thiis, P.J.A.; Tiemeijer, L.F.; Binsma, J.J.M.; Van Dongen, T. Progress in long-wavelength strained-layer InGaAs(P) quantum-well semiconductor lasers and amplifiers. IEEE J. Quantum Electron. 1994, 30, 477-499. [CrossRef]

38. Cunningham, J.E.; Goossen, K.W.; Williams, M.; Jan, W.Y. Pseudomorphic InGaAs-GaAsP quantum well modulators on GaAs. Appl. Phys. Lett. 1992, 60, 727-729. [CrossRef]

39. Miller, B.I.; Koren, U.; Young, M.G.; Chien, M.D. Strain-compensated strained layer superlattices for $1.5 \mu \mathrm{m}$ wavelength laser. Appl. Phys. Lett. 1991, 58, 1952-1954. [CrossRef]

40. Chiu, T.H.; Cunningham, J.E.; Woodward, T.K.; Sizer, T., II. Growth of strain-balanced InAsP-InGaP superlattice for $1.06 \mu \mathrm{m}$ optical modulator. Appl. Phys. Lett. 1993, 62, 340-342. [CrossRef]

41. Ayers, J.E. Heteroepitaxy of Semiconductors: Theory, Growth, and Characterization; CRC Press: Boca Raton, FL, USA, 2007.

42. Yan, C.H.; Tu, C.W. Synthesis of highly strained $\operatorname{In}_{y} \mathrm{Ga}_{1-y} \mathrm{P} / \mathrm{In}_{x} \mathrm{Ga}_{1-x} \mathrm{As} / \mathrm{In}_{y} \mathrm{Ga}_{1-y} \mathrm{P}$ quantum well structures with strain compensation. J. Cryst. Growth 1996, 164, 276-280. [CrossRef]

(C) 2018 by the authors. Licensee MDPI, Basel, Switzerland. This article is an open access article distributed under the terms and conditions of the Creative Commons Attribution (CC BY) license (http://creativecommons.org/licenses/by/4.0/). 